\title{
Determination of Local Slope on the Greenland Ice Sheet Using a Multibeam Photon-Counting Lidar in Preparation for the ICESat-2 Mission
}

\author{
Kelly M. Brunt, Thomas A. Neumann, Kaitlin M. Walsh, and Thorsten Markus, Member, IEEE
}

\begin{abstract}
The greatest changes in elevation in Greenland and Antarctica are happening along the margins of the ice sheets where the surface frequently has significant slopes. For this reason, the upcoming Ice, Cloud, and land Elevation Satellite-2 (ICESat-2) mission utilizes pairs of laser altimeter beams that are perpendicular to the flight direction in order to extract slope information in addition to elevation. The Multiple Altimeter Beam Experimental Lidar (MABEL) is a high-altitude airborne laser altimeter designed as a simulator for ICESat-2. The MABEL design uses multiple beams at fixed angles and allows for local slope determination. Here, we present local slopes as determined by MABEL and compare them to those determined by the Airborne Topographic Mapper (ATM) over the same flight lines in Greenland. We make these comparisons with consideration for the planned ICESat-2 beam geometry. Results indicate that the mean slope residuals between MABEL and ATM remain small $\left(<0.05^{\circ}\right)$ through a wide range of localized slopes using ICESat-2 beam geometry. Furthermore, when MABEL data are subsampled by a factor of 4 to mimic the planned ICESat-2 transmit-energy configuration, the results are indistinguishable from the full-data-rate analysis. Results from MABEL suggest that ICESat-2 beam geometry and transmit-energy configuration are appropriate for the determination of slope on $\sim 90-\mathrm{m}$ spatial scales, a measurement that will be fundamental to deconvolving the effects of surface slope from the ice-sheet surface change derived from ICESat-2.
\end{abstract}

Index Terms-Airborne lidar, laser altimetry, photon counting.

\section{INTRODUCTION}

$\mathbf{T}$ HE Ice, Cloud, and land Elevation Satellite-2 (ICESat-2) is a NASA mission scheduled to launch in 2016. ICESat2 is a follow-on mission to ICESat (2003-2009) and will extend the time series of elevation-change measurements aimed at estimating the contribution of polar ice sheets to sea-level rise, quantifying changes in sea ice freeboard, and enabling determination of global vegetation height. Relative to ICESat, ICESat-2 represents an opportunity to improve estimates of icesheet surface-elevation change by resolving surface slope.

ICESat carried the Geoscience Laser Altimeter System (GLAS), a single-beam laser altimeter that recorded the re-

Manuscript received June 10, 2013; revised July 30, 2013; accepted September 10, 2013.

K. M. Brunt is with Goddard Earth Sciences Technology and Research (GESTAR), NASA Goddard Space Flight Center, Greenbelt, MD 20771 USA (e-mail: kelly.m.brunt@nasa.gov).

T. A. Neumann and T. Markus are with the NASA Goddard Space Flight Center, Greenbelt, MD 20771 USA.

K. M. Walsh is with Sigma Space Corporation, NASA Goddard Space Flight Center, Greenbelt, MD 20771 USA.

Digital Object Identifier 10.1109/LGRS.2013.2282217

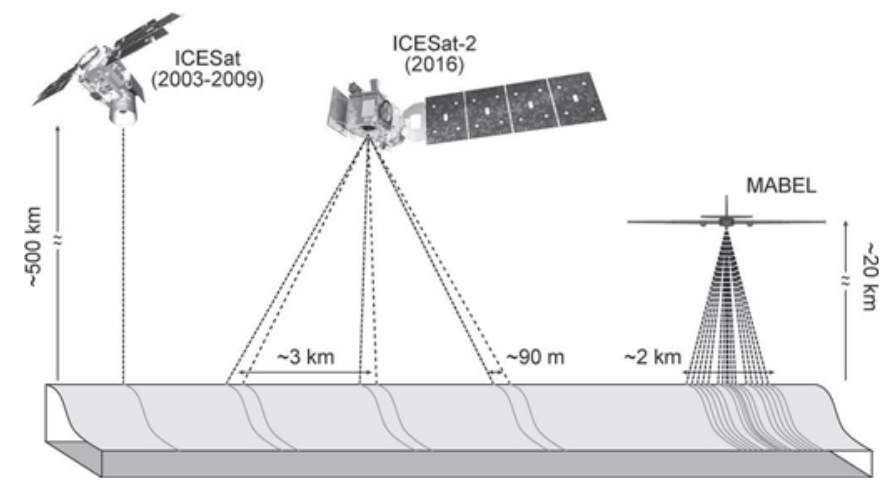

Fig. 1. (Left) Schematic ICESat, (center) ICESat-2, and (right) MABEL (dashed lines) beam geometry and (gray lines along ice-sheet surface) reference ground tracks. MABEL allows for beam-geometry changes with a maximum ground spacing of $\pm 1 \mathrm{~km}$ at $20 \mathrm{~km}$.

ceived laser energy as a waveform to determine surface elevation, based on reflected 1064-nm wavelength laser light with a $40-\mathrm{Hz}$ pulse-repetition frequency. GLAS sampled 50-70-mdiameter footprints every $\sim 172 \mathrm{~m}$ along a series of repeated tracks [1], providing information about surface elevation and local slope along track but not across track. ICESat ground tracks did not repeat exactly, further complicating the GLAS determination of surface-elevation change; the postprocessed footprints were offset from a reference ground track by up to $200 \mathrm{~m}$. Thus, for a single-beam laser altimeter, such as ICESat, change in surface elevation with respect to time is difficult to separate from the effects of local surface slope. Ultimately, to make this separation, ICESat required up to 12 passes in areas with either low slope or subtle elevation change, such as East Antarctica.

ICESat-2 will carry the Advanced Topographic Laser Altimeter System (ATLAS), which uses a different detection strategy than GLAS. Specifically, ATLAS will be a six-beam photon-counting laser altimeter using short $(<2 \mathrm{~ns}) 532-\mathrm{nm}$ wavelength pulses, with a $10-\mathrm{kHz}$ repetition rate. In a photoncounting system, single-photon sensitive detectors are used, and the arrival time of any detected photon is recorded. ATLAS will have a $\sim 10$-m-diameter footprint and a $\sim 70$-cm alongtrack sampling interval [2]. An accurate assessment of ice-sheet elevation change is dependent upon knowledge of local slope [3]. Therefore, the six beams are arranged in three sets of pairs. Spacing between the three sets of pairs is $\sim 3 \mathrm{~km}$ to increase sampling density, whereas spacing between each beam within a given pair will be $\sim 90 \mathrm{~m}$ to make the critical determination of local slope on each pass (see Fig. 1). Therefore, elevation change can be determined from only two passes of a given area. 


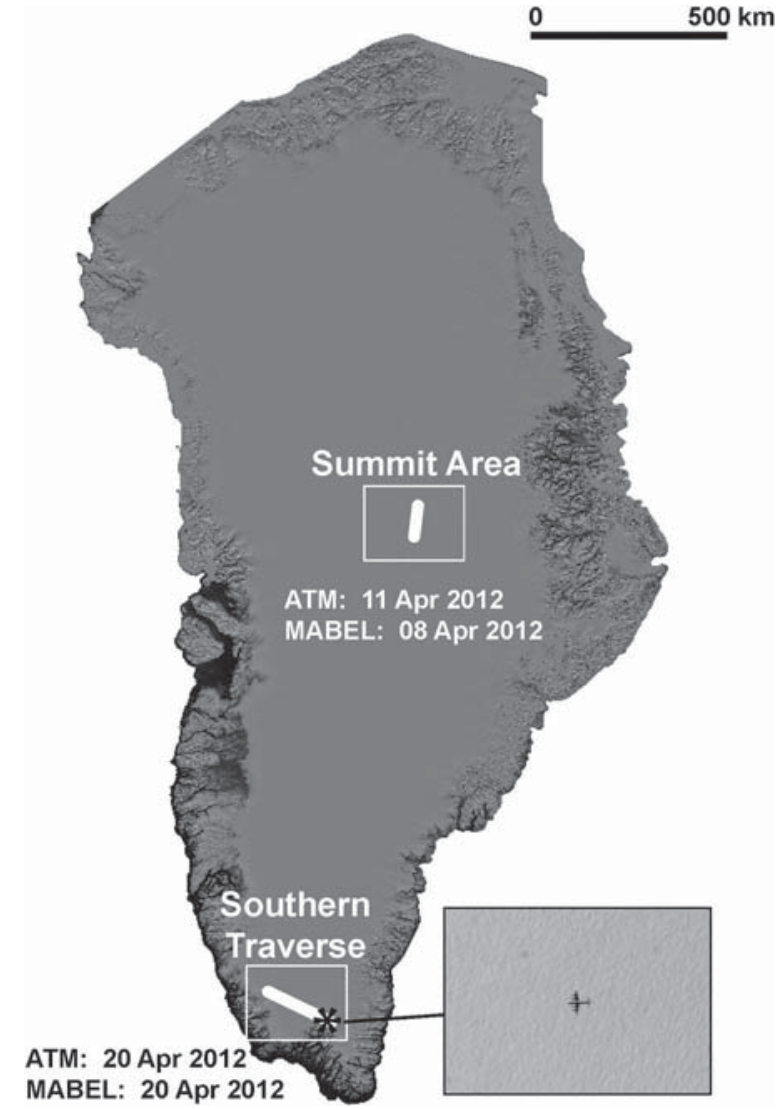

Fig. 2. Location map of the 50-km along-track Summit Area site and the 150-km along-track Southern Traverse site on the MODIS Mosaic of Greenland [17]. (Inset) Operation IceBridge P-3B captured in the NASA ER-2 Cirrus Digital Camera System [18] at the black “*”.

Given this new approach to spaceborne surface elevation measurement, an airborne instrument, the Multiple Altimeter Beam Experimental Lidar (MABEL), was developed to: 1) enable the development of ICESat-2 geophysical algorithms prior to launch; 2) provide detailed error analysis of the ATLAS measurement strategy; and 3) provide ATLAS model validation. MABEL is a photon-counting multibeam lidar sampling at both 532- and 1064-nm wavelengths using short ( 1.5-ns) laser pulses. MABEL beams are arranged in a linear array, perpendicular to the direction of flight. The system allows for beam-geometry changes between flights with a maximum view angle of $\pm 1 \mathrm{~km}$ from a $20-\mathrm{km}$ nominal altitude achieved during the 2010-2012 deployments using a NASA ER-2 aircraft (see Fig. 1). The repetition rate of MABEL is variable (between 5 and $25 \mathrm{kHz}$ ); most flights during the 2010-2012 deployments used $5 \mathrm{kHz}$. At this nominal altitude, repetition rate, and an aircraft speed of $\sim 200 \mathrm{~m} / \mathrm{s}$, MABEL samples a $\sim 2$-m footprint every $\sim 4 \mathrm{~cm}$ along track [4]. During these initial MABEL deployments, beam geometry (specifically the spacing between the individual beams) was configured to mimic ICESat-2 [5]. Following engineering test flights in December 2010 and March 2011, MABEL was deployed to Greenland in April 2012 to collect data over polar targets (see Fig. 2).

Operation IceBridge is a NASA airborne campaign intended to bridge the data gap between ICESat and ICESat-2. Operation IceBridge hosts a suite of instruments [6], including the Airborne Topographic Mapper (ATM). ATM is a lidar that conically scans at a rate of $20 \mathrm{~Hz}$, with an off-nadir scanning angle of $\sim 15^{\circ}$. Like GLAS, ATM digitizes returned energy as a waveform with derived surface elevations based on 532-nm wavelength pulses and a 5-kHz pulse-repetition frequency [7], [8]. The ATM flights used in this letter were conducted using NASA P-3B at an aircraft speed of $\sim 100 \mathrm{~m} / \mathrm{s}$, with a nominal elevation of $500 \mathrm{~m}$ above ground level. At this air speed, elevation, and repetition frequency, ATM generates a 1-m footprint and a scanning swath width of $\sim 250 \mathrm{~m}$.

Logistics and cloud-free weather allowed for coordinated surveys between ATM and MABEL over the Greenland Ice Sheet (see Fig. 2). Here, we present MABEL multibeam determination of the ice-sheet surface and compare it with that determined by ATM, including local slope assessments. These comparisons are made with consideration for the ICESat-2 planned beam geometry and relative signal strength.

\section{DAta AND Methods}

Both MABEL and ATM simultaneously surveyed a $150-\mathrm{km}$ "Southern Traverse" of the Greenland Ice Sheet on April 20, 2012 (see Fig. 2). Additionally, MABEL made three passes over a 50-km stretch of ICESat track 0412 in the vicinity of Summit Station, Greenland, on April 8, 2012. ATM made a pass of the same ground segment on April 11, 2012 (see Fig. 2). This ground segment has been used as a calibration site for ICESat [9].

The NASA IceBridge ATM Level-2 Icessn Elevation, Slope, and Roughness (ILATM2) for April 11 and 20, 2012, were obtained from the National Snow and Ice Data Center (NSIDC; http://nsidc.org/data/ilatm2.html). This is a resampled and smoothed elevation data set [10] that provides four acrosstrack elevations per timestamp every $\sim 35$-m along track, which allowed for the trivial calculation of across-track slope. The total across-track span for this data set, for the flights used in this analysis, was approximately $150 \mathrm{~m}$.

MABEL data (release 8) for April 8 and 20, 2012, were obtained from the NASA ICESat-2 website http://icesat.gsfc. nasa.gov/icesat2/). Each data file contains $1 \mathrm{~min}$ of data for every available beam. The data files contain photon arrival times resulting from reflected laser light (i.e., signal photons) and background photons due to sunlight (i.e., noise photons).

In order to discriminate coarse signal photons from noise photons and derive ice-sheet surface elevation, we developed an algorithm based on histograms of the photon data. Evolving from techniques applied to other photon-counting lidars, such as Slope Imaging Multi-polarization Photon-counting Lidar [11], we generated 0.125 -s ( $\sim 25 \mathrm{~m}$; 625 shots) along-track segments of data and histogrammed the photon data at $10-\mathrm{m}$ vertical resolution. We identify signal photons in four sequential steps. First, the mean and standard deviation of total bin counts are calculated. Bins with more counts than the mean plus the standard deviation are considered to potentially contain signal photons. Second, we exclude the potential signal bins found in step 1 and recalculate the mean and standard deviation for the remaining bins. These values primarily reflect the mean and standard deviation of the background count rate. We add bins with more than 15 times the standard deviation of background counts to the potential signal bins found in step 1. Third, we include any individual photon that is within 
$\pm 10 \mathrm{~m}$ of signal photons found in steps 1 and 2 as additional signal photons. Last, we select the median photon elevation, plus all photons within $\pm 0.5 \mathrm{~m}$ of the median elevation, as signal photons. This approach assumes that the background photons are randomly distributed and that the returned pulse is symmetric. Data from surfaces with large slopes or roughness can generate a returned pulse wider than the 1-m window of step $4(\sim 3.3 \mathrm{~ns}$ of flight time, or about 2.5 times the transmitted pulsewidth). Additional analysis of MABEL data from the ice-sheet interior indicates that the returned pulse shape is largely symmetric and less than twice the transmitted pulsewidth [12].

For direct comparison of the surveys, ATM tracks and MABEL beams were chosen to most closely mimic the $90-\mathrm{m}$ spacing of the ICESat-2 beam geometry. ATM tracks 2 and 3 were used for this analysis because they have ground separation of $\sim 85 \mathrm{~m}$. Elevations from tracks 2 and 3 from the same alongtrack time were then used to calculate ATM across-track slope. MABEL beam 6 (center of the array) and beam 5 ( 85-m ground spacing from the center of the array) were chosen for analysis as they have an across-track ground separation similar to the ATM tracks used. To determine MABEL across-track slope, signal photons from beams 5 and 6 were interpolated along track to a common time so that, similar to ATM, an across-track slope could be then calculated for each increment of along-track time. The across-track slopes for both ATM and MABEL were then compared.

MABEL beams have variable signal strengths; however, beams 5 and 6 are the most similar to the expected radiometry of the strong beams of ATLAS. Along-track data density differed within and between flights based on variables that affect reflectivity, including weather conditions, time of day, and sun-incidence angle. For the data used in this analysis, the full-rate along-track data density average for both beams was always greater than 4 signal photons/m. For the Southern Traverse flight, the along-track data densities were 3.4 and 3.9 signal photons per $70 \mathrm{~cm}$ for beams 5 and 6 , respectively. For the Summit Area flight, data densities were 3.1 and 3.4 signal photons per $70 \mathrm{~cm}$ for beams 5 and 6 , respectively.

A strong-beam/weak-beam pair will be used for ICESat-2 slope determination; the energy associated with the weak beam will be reduced by a factor of 4 . Therefore, the expected number of signal photons per laser shot (every $70 \mathrm{~cm}$ along track) between the strong beam and the weak beam will also differ by a factor of 4 . The current best estimates of expected signal photons per laser shot vary with season and surface type. Based on ICESat-2 engineering models, under similar conditions as the 2012 MABEL survey, we expect ICESat-2 to record 8.5 and 2.1 signal photons every shot (or $70 \mathrm{~cm}$ along track) for the strong and weak beams, respectively [13]. Thus, the MABEL full-rate data used in this analysis suggest data densities of $46 \%$ of the expected ICESat-2 data densities. MABEL engineers are currently working to increase signal strength to achieve the expected ICESat-2 data densities, which will facilitate more direct MABEL to ATLAS comparisons.

To further assess accurate ground characterization given the ICESat-2 planned configuration, all photons associated with one of the MABEL beams (beam 5) were subsampled by a factor of 4 and then reprocessed through the ground-finding algorithm, to simulate the expected radiometric relationship be- tween the ATLAS strong and weak beams. After subsampling, data densities were 0.9 and 0.8 signal photons per $70 \mathrm{~cm}$ for the Southern Traverse and Summit Area, respectively. To determine MABEL across-track slope, the ground-signal photons from beam 6 and the subsampled ground-signal photons from beam 5 were again interpolated to a common time so that an acrosstrack slope could be calculated as described above. Therefore, the beam with the fewest along-track samples (the weak beam, 5) limited the total number of samples that was used in the slope determination.

\section{RESULTS}

\section{A. MABEL Accuracy and Precision}

ATM is calibrated each flight by comparing airborne lidar elevations with elevations derived from a ground-based GPS survey of a portion of the departure airport apron (in this case, a 1.4-km along-track portion of the Kangerlussuaq, Greenland airport apron). The Kangerlussuaq GPS ground survey data (differentially postprocessed with an RMS $<5 \mathrm{~cm}$ ) were provided by the ATM project [14], which allowed us to make an assessment of the ATM precision for flights on April 11 and 20, $2012( \pm 16.3 \mathrm{~cm})$. MABEL overflew the apron during the April 20,2012 , flight, allowing for the determination of the accuracy and precision of the elevations derived from the ground-finding algorithm for both of the 532-nm beams used in this analysis (beams 5 and $6:-1.99 \mathrm{~m} \pm 14 \mathrm{~cm}$ and $-1.76 \pm 14 \mathrm{~cm}$, respectively). MABEL elevations from each beam were then corrected independently based on these biases.

\section{B. MABEL Local Slope Assessment}

Along the Southern Traverse, ATM and MABEL both collected data along a transect across the Greenland Ice Sheet, including a wide range of elevations and slopes (see Fig. 3); in general, the eastern flank of this traverse is much steeper than the western flank. The ground surface detected by MABEL traced that determined by ATM [see Fig. 3(b)]. Visual assessment of the across-track slope results indicated that relative to ATM, MABEL is able to determine the character of the surface throughout a wide range of slopes [see Fig. 3(c)]. The mean slope values along the Southern Traverse for ATM and MABEL were $0.99^{\circ}$ and $1.03^{\circ}$, respectively, with a mean slope residual between the two sensors of $0.03^{\circ}$.

Similar results were observed at the Summit Area site, which is very flat relative to the Southern Traverse flight line (see Fig. 4; note the change in the scale of the $y$-axes, relative to Fig. 3). Again, the ground surface detected by MABEL traces that determined by ATM [see Fig. 4(a)]. The mean slope values for the Summit Area for ATM and MABEL were $0.07^{\circ}$ and $0.11^{\circ}$, respectively, with a mean slope residual between the two sensors of $0.04^{\circ}$.

\section{Elevation Uncertainty}

Surface elevation uncertainty is related to geolocation (horizontal) uncertainty and local slope angle $\alpha$ [15]

elevation uncertainty $=\tan (\alpha) \times$ horizontal uncertainty. 

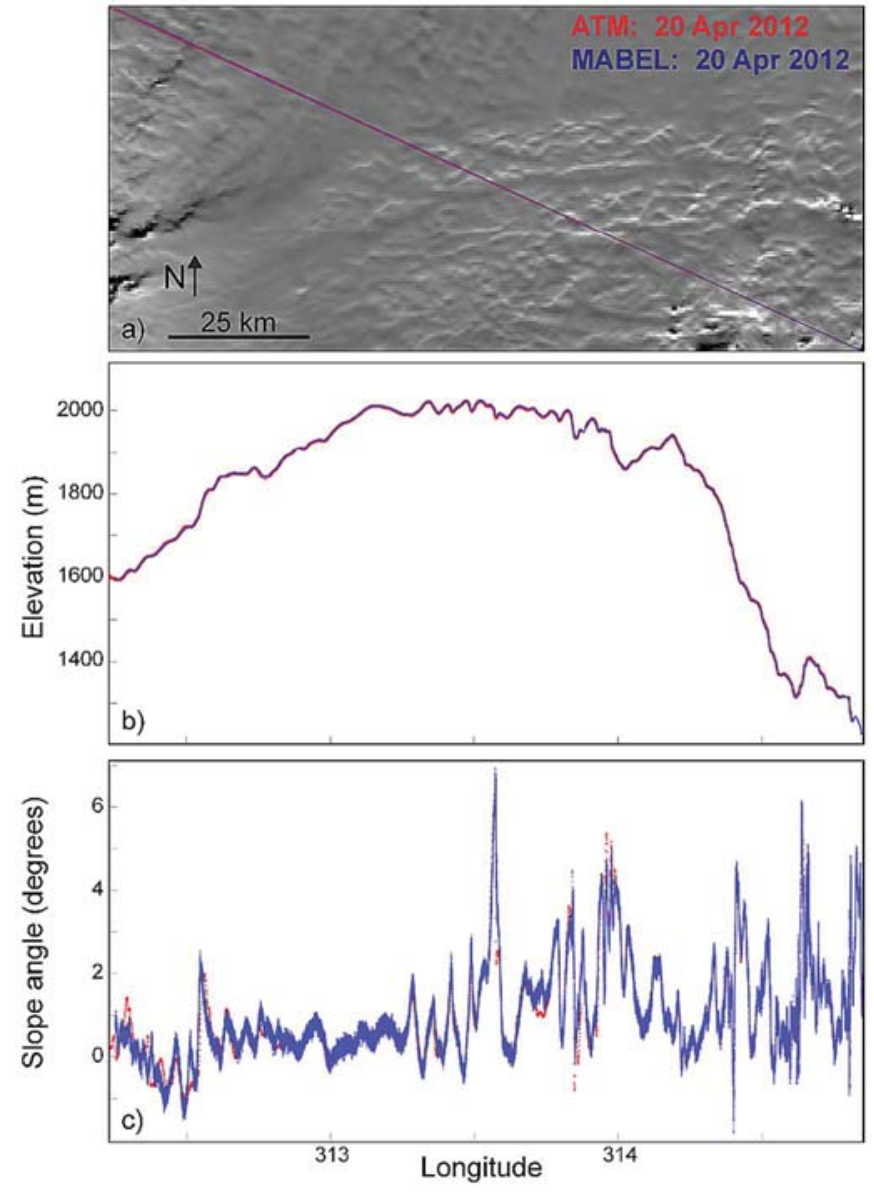

Fig. 3. ATM and MABEL data, from the same day, along the Southern Traverse sampling site (see Fig. 2). (a) MODIS Mosaic of Greenland [17] with (red) ATM and (blue) MABEL flight paths. (b) ATM and MABEL elevations along the flight paths. (c) ATM and MABEL across-track slope angles in degrees.

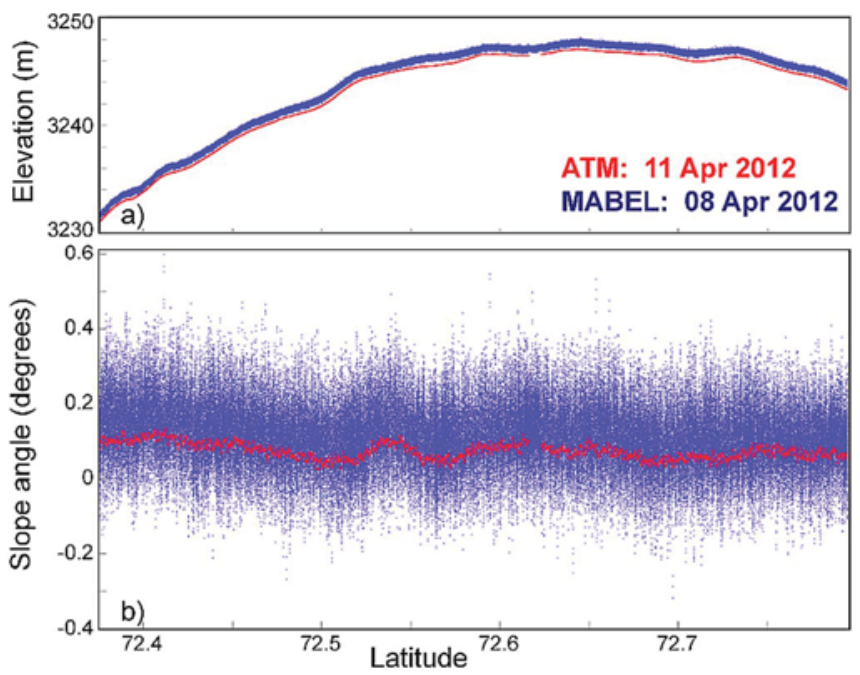

Fig. 4. ATM and MABEL data along the Summit Area sampling site (see Fig. 2). (a) (red) ATM and (blue) MABEL elevations along the ground tracks. (b) ATM and MABEL across-track slope angles in degrees; note that the scales of the $y$-axes are substantially different from Fig. 3 .

MABEL has geolocation knowledge of $0.1 \mathrm{mrad}\left(0.0057^{\circ}\right)$ [16]; for a $20-\mathrm{km}$ nominal altitude, this produces a $2-\mathrm{m}$ horizontal uncertainty on the surface. Based on (1) and the range of
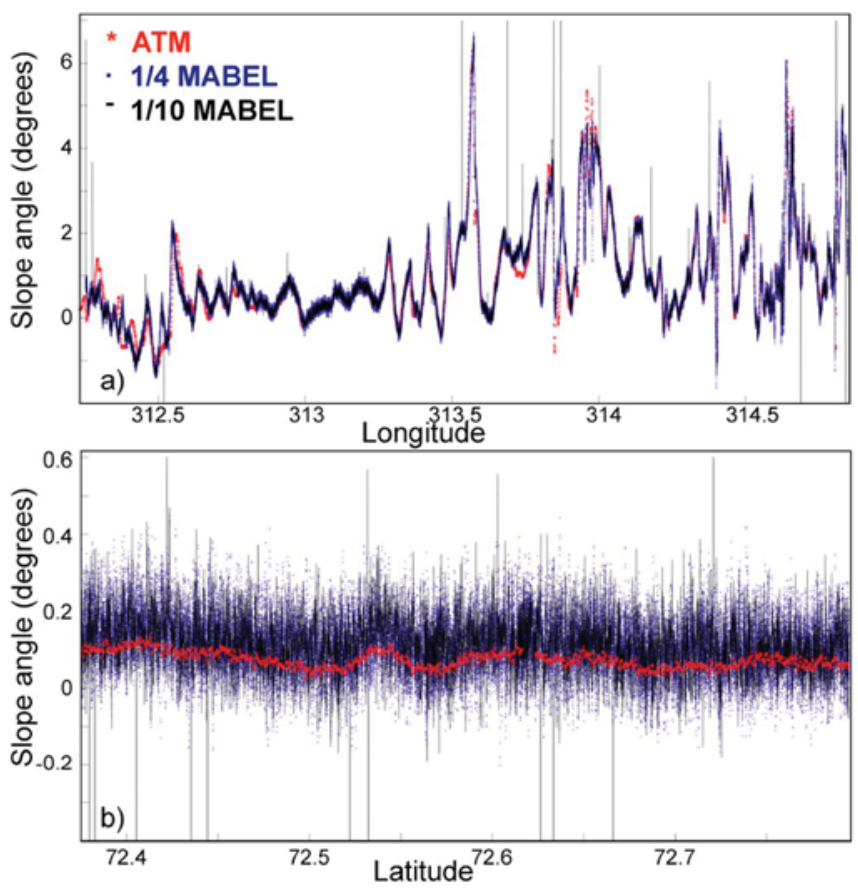

Fig. 5. Across-track slope angles based on ATM and simulated weak-beam MABEL along the (a) Southern Traverse and (b) Summit Area sampling sites. Across-track slope angles for (red) ATM and MABEL subsampled by factors of (blue) 4 and (black) 10; at a subsampling rate of 10, the standard deviation of the slope differs.

slope values for the Summit Area [with a minimum of $\sim 0.1^{\circ}$ from Fig. 4(b)] and the Southern Traverse [with a maximum of $6^{\circ}$ from Fig. 3(c)], MABEL geolocation-induced elevation uncertainties for this letter will range from 0.4 to $21 \mathrm{~cm}$, respectively.

The other major sources of elevation uncertainty are due to errors in the surface-finding algorithm and time-tag errors within MABEL. Laboratory evaluation shows that the timing precision of MABEL is $\sim 200 \mathrm{ps}$ (or $3 \mathrm{~cm}$ of range). While the contribution from the algorithm is difficult to definitively assess, it is significantly less than the return pulsewidth ( 1.8-ns full-width at half maximum); therefore, we assume a value of $15 \mathrm{~cm}$. Taking the square root of the sum of the squares of these terms leads to a cumulative elevation uncertainty range of $15-26 \mathrm{~cm}$.

\section{MABEL Subsampled Assessment of Local Slope}

The slopes based on the MABEL ground signal subsampled by a factor of 4 were robust with respect to ATM slope determination and the full-rate MABEL ground signal [compare Fig. 5 to Figs. 3(c) and 4(b)]. The across-track slopes derived from subsampled ground-signal photons, for both the variable terrain of the Southern Traverse and the flat terrain of the Summit Area, were statistically indistinguishable from the MABEL full-rate across-track slopes.

When the photons associated with full-rate beam 5 were subsampled by a factor of 10 , substantially reducing the data rates of the simulated weak beam (to 0.3 signal photons per $70 \mathrm{~cm}$ for both the Southern Traverse and the Summit Area), relative to ATM and the full-rate MABEL data, the mean slope values for both study areas remained relatively unchanged (see Fig. 5). However, the standard deviations of the slopes differed. 
For the Southern Traverse, the mean slope slightly decreased from $1.03^{\circ}$ to $0.98^{\circ}$, whereas the standard deviation changed from $1.14^{\circ}$ to $2.41^{\circ}$. For the Summit Area, the results were more dramatic; the mean slope decreased from $0.11^{\circ}$ to $-0.43^{\circ}$, whereas the standard deviation changed from $0.09^{\circ}$ to $5.87^{\circ}$. These changes in the standard deviation of the data (seen as outliers in Fig. 5) suggest that the subsampling of the fullrate MABEL photon data is having an adverse effect on the ground-finding algorithm. While the ground-finding algorithm could be modified to search for the surface on different alongtrack spatial scales, these results give us confidence that even when subsampled by a factor of 10, MABEL signal strength is sufficient to determine ice-sheet slope on $\sim 90$-m length scales.

\section{CONCLUSION}

As determined in previous studies, MABEL photon-counting lidar data have provided precise knowledge of the along-track ground surface [4], [5]. Subsequent releases of the data, which include beam-angle calibrations, indicate that the MABEL ground signal has $<2$-m accuracy and \pm 14 -cm precision for the April 20, 2012, flight. While instrument accuracy is larger than that of other airborne lidars, it is within the MABEL design goals (algorithm development, error analysis, and ATLAS model validation), where instrument precision is more critical to satellite algorithm development.

Using the release $8 \mathrm{MABEL}$ data, which include beam-angle calibrations, we were able to simultaneously analyze multiple beams to determine that the lidar accurately characterizes the ice-sheet surface, as demonstrated by comparisons of slope on 90-m spatial scales with ATM measurements. By analyzing data from both variable (Southern Traverse) and flat (Summit Area) terrains, we also demonstrate that MABEL slopedetermination capabilities remain robust through a wide range of localized slope assessments.

Finally, in preparation for the launch of ICESat-2, we assessed MABEL local across-track slope determination using similar beam spacing and a similar transmit-energy-strength relationship between a strong and simulated weak-beam pair. While the April 2012 MABEL data densities are, at best, 46\% of the current expectations for ICESat-2, the slope determination using a simulated weak beam based on photon counts subsampled by a factor of 4 remained robust. However, at a subsampling rate of 10 , while the mean slope values for both study areas remained relatively unchanged from the full-rate MABEL ground signal, the changes in the standard deviation of the data suggest that the subsampling of the MABEL photons is having an adverse effect on the ground-finding algorithm.

The results based on MABEL give us confidence in the ICESat-2 measurement strategy, with respect to beam geometry and the transmit-energy-strength relationship. This measurement strategy allows for the separation of the effects of local slope from true ice-sheet elevation change with just two satellite passes of a given area.

\section{ACKNOWLEDGMENT}

The authors would like to thank M. McGill, W. Cook, E. De Marco, D. Reed, S. Disque, and W. Hart for MABEL support; D. Hancock, J. Lee, C. Webb, and S. Luthcke for MABEL calibration; NASA/Dryden Air Operations Facility (specifically pilots T. Williams and D. S. Broce) for Greenland field support; Operation IceBridge for coordinated flights; K. Krabill for GPS data; NASA Airborne Science Program, Airborne Sensor Facility for imagery; National Snow and Ice Data Center for Airborne Topographic Mapper data distribution; and two anonymous reviewers for constructive comments.

\section{REFERENCES}

[1] B. Schutz, H. Zwally, C. Shuman, D. Hancock, and J. DiMarzio, "Overview of the ICESat mission," Geophys. Res. Lett., vol. 32, no. 21, p. L21S01, 2005.

[2] W. Abdalati, H. Zwally, R. Bindschadler, B. Csatho, S. Farrell, H. Fricker, D. Harding, R. Kwok, M. Lefsky, T. Markus, A. Marshak, T. Neumann, S. Palm, B. Schutz, B. Smith, J. Spinhirne, and C. Webb, "The ICESat-2 laser altimetry mission," Proc. IEEE, vol. 98, no. 5, pp. 735-751, May 2010.

[3] H. Zwally, J. Li, A. Brenner, M. Beckley, H. Cornejo, J. DiMarzio, M. B. Giovinetto, T. Neumann, J. Robbins, J. Saba, D. Yi, and W. Wang, "Greenland ice sheet mass balance: Distribution of increased mass loss with climate warming; 2003-07 vs. 1992-02," J. Glaciol., vol. 57, no. 201, pp. 88-102, 2011.

[4] M. McGill, T. Markus, V. Scott, and T. Neumann, "The multiple altimeter beam experimental lidar (MABEL), an airborne simulator for the ICESat-2 mission," J. Atmos. Ocean. Technol., vol. 30, no. 2, pp. 345-352, Feb. 2013.

[5] K. Brunt, T. Neumann, T. Markus, W. Cook, W. Hart, C. Webb, J. Dimarzio, D. Hancock, J. Lee, S. Bhardwaj, A. Brenner, D. Yi, C. Carabajal, and D. Harding, "MABEL photon-counting altimetry data for ICESat-2 simulations," in Proc. AGU Fall Meet. Abstracts, Dec. 2011.

[6] L. Koenig, S. Martin, M. Studinger, and J. Sonntag, "Polar airborne observations fill gap in satellite data," EOS Trans. AGU, vol. 91, no. 38, pp. 333-334, Sep. 2010.

[7] W. Krabill, W. Abdalati, E. Frederick, S. Manizade, C. Martin, J. Sonntag, R. Swift, R. Thomas, and J. Yungel, "Aircraft laser altimetry measurement of elevation changes of the Greenland ice sheet: Technique and accuracy assessment," J. Geodyn., vol. 34, no. 3/4, pp. 357-376, Oct./Nov. 2002.

[8] R. Kwok, G. Cunningham, S. Manizade, and W. Krabill, "Arctic sea ice freeboard from IceBridge acquisitions in 2009: Estimates and comparisons with ICESat," J. Geophys. Res., vol. 117, p. C02018, Feb. 2012.

[9] M. Siegfried, R. Hawley, and J. Burkhart, "High-resolution ground-based GPS measurements show intercampaign bias in ICESat elevation data near Summit, Greenland," IEEE Trans. Geosci. Remote Sens., vol. 49, no. 9, pp. 3393-3400, Sep. 2011.

[10] W. Krabill, "IceBridge ATM L2 Icessn elevation, slope, and roughness. Version 1 (ILATM2)," NASA DAAC at the National Snow and Ice Data Center, Boulder, CO, USA, 2010.

[11] D. Harding, J. Abshire, P. Dabney, A. Seas, C. Shuman, X. Sun, S. Valett, A. Vasilyev, T. Yu, T. Huss, J. Marzouk, and Y. Zheng, "The swath imaging multi-polarization photon-counting lidar (SIMPL): A spaceflight prototype," in Proc. IEEE Int. Geosci. Remote Sens. Symp., 2008, pp. 6-11.

[12] T. Neumann, T. Markus, W. Cook, K. Brunt, K. Walsh, D. Hancock, A. Brenner, E. DeMarco, and B. Csatho, "Airborne ICESat-2 simulator (MABEL) results from Greenland," in Proc. AGU Fall Meet. Abstracts, Dec. 2012.

[13] A. Martino, private communication, 2013.

[14] K. Krabill, private communication, 2013.

[15] M. Hodgson and P. Bresnahan, "Accuracy of airborne lidar-derived elevation: Empirical assessment and error budget," Photogramm. Eng. Remote. Sens., vol. 70, no. 3, pp. 331-340, 2004.

[16] S. Luthcke, private communication, 2013.

[17] T. Haran, T. Scambos, and J. Bohlander, "Updated MODIS-derived ice sheet data sets for Antarctica and Greenland: MOA 2009, MOG 2010 mosaics and products," in Proc. AGU Fall Meet. Abstracts, Dec. 2011, p. C31A-0606.

[18] C. Elvidge, P. Cinzano, D. Pettit, J. Arvesen, P. Sutton, C. Small, and S. Ebener, "The Nightsat mission concept," Int. J. Remote Sens., vol. 28, no. 12 , pp. 2645-2670, 2007. 